\title{
Differences in self-compassion and shame-proneness in patients with borderline personality disorder, eating disorders, alcohol-addiction and in healthy controls: Is the narrative self at fault for everything?
}

\begin{abstract}
Objectives: The lack of self-compassion and shame-proneness may both be associated with a wide range of mental disorders. The aim of this study was to compare the levels of compassionate self-responding and shame-proneness in samples of patients with borderline personality disorder, eating disorders, alcohol-addiction and in healthy controls.
\end{abstract}

Methods: All three clinical groups and healthy controls were administered scales measuring self-compassion (SCS) and shame-proneness (TOSCA-3S). Differences in compassionate self-responding and shame-proneness were analyzed and effect sizes were calculated.

Results: All three clinical groups were found to have significantly lower compassionate self-responding and significantly higher shame-proneness than healthy controls. The magnitudes of difference in compassionate self-responding and shame-proneness, between all clinical groups and healthy controls, were moderate to large.

Conclusions: We hypothesize, that implicit belief in self as a permanent entity together with the lack of self-compassion leads to increased shame-proneness, which causes various psychopathological symptoms. We assume, that clients suffering from all these disorders may benefit from treatments or particular interventions that facilitate the development of selfcompassion or shame management. 
Keywords: self-compassion; shame-proneness; narrative self-referential processing; transdiagnostic factors; clinical samples

\section{Introduction}

Self-conscious emotions such as authentic pride, hubristic pride, shame, guilt or embarrassment arise as a result of the appraisal of one's own behaviour or oneself in a social context, and may be both adaptive and maladaptive. According to Tangney and Dearing (2002), the feeling of guilt, for example, relates to specific behaviour ("What I did") and encourages us to learn something from specific mistakes we make. It is therefore usually considered adaptive. On the contrary, shame associated with feelings of inadequacy, inferiority and worthlessness, arises as a consequence of fairly global negative evaluations of the self ("Who I am") and encourages us to seek to hide or conceal our deficiencies. It is therefore considered maladaptive (Tangney \& Dearing, 2002). Shame is a consequence of narrative self-referential processing and its origin is partly due to our self-image or the so-called narrative self (see Gallagher, 2000). But as no solid, permanent self exists in reality, this self-image is always only an illusion. The origin of shame is thus conditioned by illusion that traditional Buddhist psychology terms the "illusion of self" (Albahari, 2016, cf. Thompson, 2014). Is it possible that this illusion, combined with heightened self-criticism, is a hidden cause of mental disorders?

In current Western psychology there are theories that directly or indirectly highlight the important role of the illusory, narrative self in the etiopathogenesis of mental disorders. Moore et al. (2017), for example, consider the so-called hyper-egoicism as a transdiagnostic factor present in a whole range of mental disorders. Clients suffering from a range of disorders are, according to these authors, inclined inter alia to (1) "spend excessive cognitive resources thinking about and evaluating the meaning and implications of their thoughts, feelings, and motives"; and (2) "use an ISG (internal, stable, global) attributional style, making broad 
generalizations about themselves that are apt to be abstract in nature" (Moore et al., 2017). Shonin, Van Gordon, \& Griffiths (2016) speak in this context of so-called ontological addiction, which "refers to the maladaptive condition whereby an individual is addicted to the belief that they inherently exist (i.e., as an independent and autonomous entity)". They also consider this “core belief” to be a hidden cause of many mental disorders (cf. Van Gordon et al., 2018). There are also neurobiological studies focusing on (negative) self-referential processing in mental disorders (van Oort et al., 2020; cf. Frewen et al., 2020; Winter et al., 2020). Let us return however to the feeling of shame.

According to our clinical experience, shame is present covertly in many mental disorders, even though our attention is usually attracted by other, more obvious symptoms (see also e.g. Cândea \& Szentagotai, 2013; Kyrios et al., 2016; Scheel et al., 2014). Clients with anxiety disorders, for example, are often unable to rid themselves of compulsive, catastrophic thoughts and ideas associated with feelings of anxiety. Yet what are they actually afraid of? Death? Our experience is that deep in their souls they fear the feeling of failure and also rejection or condemnation by others. They are afraid they will not be "good enough" for others. Deep in their souls they are thus experiencing shame (see also e.g. Cândea \& Szentagotai-Tătar, 2018a, b). Rumination in clients with depression is also typically connected with ruthless, unconstructive and undifferentiated self-criticism and self-blame. Clients suffering from depression also therefore evoke feelings of shame in themselves (see also e.g. Kim, Thibodeau, \& Jorgensen, 2011). Clients with personality disorders are perfectionists and frequently show off, yet at the same time avoid closeness in relationships. Why? Their behaviour is also clearly intended to avert experiencing painful feelings of inadequacy or shame (see also e.g. Peters \& Geiger, 2016; Ritter et al., 2014). The situation is similar with eating disorders, where the narrative self practically merges with the supposedly imperfect body. Clients with eating disorders almost constantly obsess about their appearance, long for a perfect body, and fear 
being overweight. Why? They also fear the rejection or condemnation of others as they feel inadequate or, in other words, they experience shame (see also e.g. Amianto et al., 2016; Duarte, Ferreira, \& Pinto-Gouveia, 2016). Finally, with substance use disorders we also assume the hidden influence of shame on the formation of addiction. This is because substance use allows escape from and the avoidance of painful feelings of shame, but also leads to behaviours that trigger shame. This link between shame and substance use gives rise to a vicious circle (see also e.g. Luoma, Chwyl, \& Kaplan, 2019).

Yet is it possible to effectively prevent shame in any way? The development of mindfulness leads to a change in perspective on the self (Dahl, Lutz, \& Davidson, 2015; Engler \& Fulton, 2012; Giles, 2019; Lin, Callahan, \& Moser, 2018; Shapiro, Siegel, \& Neff, 2018). And we can suppose that a gradual abandoning of attachment to the idea of an inherently existing self eliminates feelings of shame. Similarly, however, we can also prevent the formation of shame through self-compassion, meaning an attitude that is the opposite of exaggerated self-criticism (e.g. Boersma et al., 2015). Self-compassion, according to Neff (2011), represents an emotionally positive attitude toward the self in instances of perceived failure, inadequacy, or personal suffering. It can be considered an antidote to shame.

A lack of self-compassion has been demonstrated in anxiety disorders (e.g. Cândea \& Szentágotai-Tătar, 2018b), depressive disorders (e.g. López, Sanderman, \& Schroevers, 2018), personality disorders (Scheibner et al., 2017), eating disorders (Braun, Park, \& Gorin, 2016), and also substance use disorders (Brooks et al., 2012). Nevertheless, up to this point there have only been a few studies focused simultaneously on both self-compassion and shame in clinical populations (e.g. Ferreira, Pinto-Gouveia, Duarte, 2013; Kelly, Carter, Borairi, 2014). Benda, Kadlečík, \& Loskotová (2018) recently compared the levels of self-compassion, shameproneness and internalized shame in samples of patients with anxiety disorders, patients with 
depressive disorders, and in healthy controls. In this study, we examined three additional clinical samples. The goal of this study was to compare the levels of compassionate selfresponding and shame-proneness in patients with borderline personality disorders, with eating disorders, with alcohol dependence, and in healthy controls.

\section{Method}

\section{Participants}

One hundred and eighty-four clinical patients and one hundred and eighty healthy controls participated in this study. All participants had to be at least 18 years old. All clinical participants were recruited from 17 psychiatric facilities ${ }^{1}$ in the Czech Republic. They were all diagnosed by experienced psychiatrists according to ICD-10 diagnostic criteria (WHO, 1992). Patients with borderline personality disorder (BPD sample) were included if they presented with a primary diagnosis of emotionally unstable personality disorder (code F60.3). Patients with eating disorders (eating disorder sample) were included if they 1) presented with a primary diagnosis of anorexia nervosa or bulimia nervosa (code F50.0 or F50.2) and 2) had a rating of 15 or higher on the three eating-disorder-specific subscales of the EDI scale (this score indicates clinically significant eating pathology, see Garner, Olmstead, \& Polivy, 1983). Patients with alcohol-addiction (alcohol-dependent sample) were included if they 1) presented with a primary diagnosis of alcohol dependence (code F10.2) and 2) had a rating of 20 or higher on the AUDIT scale (this score indicates clinically significant alcohol use problems, see Babor et al., 2001). Patients who did not meet the inclusion criteria were excluded.

\footnotetext{
${ }^{1}$ We would like to thank the medical staff of Psychiatric Hospitals in Červený Dvưr, Kosmonosy, Kroměříž, Havlíčkův Brod, Prague-Bohnice, and Opava, Anabell Center in Prague, Kaleidoskop - Center for therapy and education in Prague, the Psychotherapeutic and Psychosomatic Clinic ESET in Prague, Fokus Praha, Hélio - Center for Mental Health in Prague, Departments of Psychiatry at the General University Hospital in Prague, the Military University Hospital Prague, the Institute for Clinical and Experimental Medicine in Prague, the University Hospital Olomouc, the Military Hospital Olomouc and the Regional Hospital Jičín for their kind cooperation.
} 
Healthy controls were recruited online through an advertisement inviting participants with an interest in self-knowledge to participate in a study concerning the attitude toward the self (shame versus self-compassion). The advertisement was posted on Facebook. All Facebook users residing in the Czech Republic were targeted. Respondents were eligible if they had a rating of 9 or less on the GAD-7 scale and the PHQ-9 scale. Participants were excluded from this sample if they reported a history of any mental disorder or if they had a score $\geq 10$ on the GAD-7 scale or the PHQ-9 scale. The sample is the same as was used in the previous study by Benda, Kadlečík \& Loskotová, 2018.

Table 1 Demographic characteristics of study participants.

\begin{tabular}{lllll}
\hline & $\mathrm{N}$ & age $(\mathrm{SD})$ & males & females \\
\hline BPD sample & 74 & $31.55(8.58)$ & 20 & $54(73 \%)$ \\
Eating disorder sample & 55 & $26.18(9.10)$ & 0 & $55(100 \%)$ \\
Alcohol-dependent sample & 55 & $43.25(11.64)$ & 34 & $21(38.2 \%)$ \\
Healthy controls & 180 & $40.55(8.43)$ & 62 & $118(65.6 \%)$ \\
\hline
\end{tabular}

The final sample consisted of 74 patients with borderline personality disorder, 55 patients with eating disorders, 55 patients with alcohol-addiction and 180 healthy controls. Demographic characteristics of each sample are shown in Table 1.

Procedure

All participants were informed about the purpose of the study. Clinical participants were first given verbal and written information about the study and they were informed that their participation was voluntary, and they were free to leave at any time. After enrolment, all clinical participants signed the informed consent and filled in the measures evaluating compassionate self-responding, shame-proneness and the severity of their clinical symptoms together with some basic demographic questions. Online participants were given written information about the purpose of the study and they were informed that all responses would be anonymous and 
confidential. Subsequently, they filled in the measures evaluating compassionate selfresponding, shame-proneness, anxiety symptoms and depressive symptoms together with some basic demographic questions.

\section{Measures}

Compassionate self-responding Compassionate self-responding was assessed using the Self-Compassion Scale (SCS, Neff, 2003; Czech version Benda \& Reichová, 2016). The original SCS has 26 items measuring six facets of self-compassion - three positive facets (i.e. self-kindness, common humanity, and mindfulness) as well as three negative facets (i.e. selfjudgment, isolation, and overidentification). However, the inclusion of the negative facets in the total score of the scale has been criticized by some authors (e.g. Brenner et al., 2018; Halamová et al., 2020; Muris, Otgaar, Pfattheicher, 2019). Therefore, only the positive subscales were used in this study as a measure of compassionate self-responding (see also Neff, 2019; Neff et al., 2018). Respondents rated 13 statements on a five-point Likert-type scale (from $1=$ almost never to $5=$ almost always). Only the sum of scores of these 13 positive items was used for the statistical analysis.

Shame-proneness Shame-proneness was assessed using the short form of the Test of SelfConscious Affect-3 (TOSCA-3S, Tangney, Dearing, 2003; Czech version Dvořáková, 2013). Respondents were presented with a series of 11 situations (scenarios) they may encounter in daily life. Each scenario was followed by 4 possible responses to the situation. Respondents rated the likelihood of each response on a five-point Likert-type scale (from $1=$ not likely to 5 $=$ very likely). The measure assesses the four personality traits: 1) shame-proneness, 2) guiltproneness, 3) externalization (blaming others and circumstances) and 4) detachment/unconcern. For the purposes of the present study, only the shame-proneness subscale of the TOSCA-3S was used. 
Anxiety symptoms To assess anxiety symptoms in healthy controls, the Generalized Anxiety Disorder-7 was used (GAD-7; Spitzer et al., 2006, Kroenke et al., 2010; Czech version Daňsová, 2015). The GAD-7 has seven items describing the severity of the patient's anxiety over the past 2 weeks. Respondents rated each statement on a four-point Likert-type scale (from $0=$ not at all to $3=$ nearly every day). The GAD-7 scores can range from 0 to 21 , and a cut point of $\geq 10$ denotes a screening cut point for clinically significant anxiety. In this study, respondents with a score of $\geq 10$ were excluded from the sample of healthy controls. The sum of scores of the GAD-7 items was used for the statistical analysis.

Depressive symptoms To assess depressive symptomatology in healthy controls, the Patient Health Questionnaire-9 was used (PHQ-9; Kroenke, Spitzer, Williams, 2001, Kroenke et al., 2010; Czech version Daňsová et al., 2016). The PHQ-9 has nine items describing the severity of the patient's depression over the past 2 weeks. Respondents rated each statement on a four-point Likert-type scale (from $0=$ not at all to $3=$ nearly every day). The PHQ-9 scores can range from 0 to 27 , and a cut point of $\geq 10$ denotes a screening cut point for clinically significant depression. In this study, respondents with a score of $\geq 10$ were excluded from the sample of healthy controls. The sum of scores of the PHQ-9 items was used for the statistical analysis.

Eating disorders symptoms To assess eating disorders symptomatology in patients with eating disorders, the Eating Disorder Inventory was used (EDI; Garner, Olmstead, \& Polivy, 1983; Czech version Papežová, 2010). The EDI comprises 64 questions, divided into eight subscales. Only the eating-disorder-specific subscales (i.e. Drive for Thinness, Bulimia and Body Dissatisfaction) were used in this study. Respondents rated each statement on a six-point Likert-type scale (from never to always). The total score of the selected subscales can range from 0 to 69 , and a cut point of $\geq 15$ denotes a screening cut point for clinically significant 
eating pathology. Respondents with a score of $<15$ were excluded from the eating disorder sample.

Alcohol dependence symptoms To assess alcohol dependence severity in patients with alcohol-addiction, the Alcohol Use Disorders Identification Test was used (AUDIT; Babor et al., 2001; Czech version Sovinová \& Csémy, 2010). The AUDIT has ten items regarding the frequency of alcohol consumption and the amount of alcohol consumed. Respondents rated each statement on a five-point Likert-type scale (rated from 0 to 4). The AUDIT scores can range from 0 to 40 points, and a cut point of $\geq 20$ denotes a screening cut point for clinically significant alcohol use problems. Respondents with a score of $<20$ were excluded from the alcohol-dependent sample.

\section{Data Analyses}

Data was analyzed using the IBM SPSS Statistics software, Version 23. Associations between study variables in all samples were determined by using correlation analyses. Pearson correlation values were interpreted according to Cohen (1988). Demographic differences between samples were tested using one-way analysis of variance for age and the chi-square test for gender distribution. Differences in compassionate self-responding and shame-proneness were tested using two separate two-way univariate analyses of covariance with Bonferroni posthoc tests. The effect sizes of differences between groups were then calculated in terms of Cohen's d.

\section{Results}

Correlations between study variables in all samples

As expected, compassionate self-responding was significantly negatively correlated with shame-proneness in almost all samples. The only exception was the alcohol-dependent sample 
(see Table 2). Concerning the correlations of compassionate self-responding and shameproneness with the severity of clinical symptoms, shame-proneness was positively correlated with anxiety symptoms $(\mathrm{r}=.37, \mathrm{p}<.001)$ and with depressive symptoms $(\mathrm{r}=.42, \mathrm{p}<.001)$ in healthy controls. Compassionate self-responding was significantly negatively correlated only with eating disorders symptoms in eating disorder sample $(\mathrm{r}=-.41, \mathrm{p}<.01)$. All remaining correlations between observed variables were not statistically significant.

Table 2 Correlations between compassionate self-responding and shame-proneness

\begin{tabular}{lc}
\hline BPD sample & $-.46^{* *}$ \\
Eating disorder sample & $-.33^{*}$ \\
Alcohol-dependent sample & -.01 \\
Healthy controls & $-.27^{* *}$ \\
\hline
\end{tabular}

${ }^{*} \mathrm{p}<.05 ; * * \mathrm{p}<.01$

Between-group differences in compassionate self-responding and shame-proneness

The samples differed significantly in age $(\mathrm{F}(3,360)=52.407, \mathrm{p}<.001)$ and gender $(\chi 2(3$, $\mathrm{N}=364)=78.920, \mathrm{p}<.001)$. Therefore, to determine if there were significant group differences in study variables, two two-way ANCOVAs were conducted with the group and gender as fixed factors, age as a covariate and compassionate self-responding and shame-proneness as dependent variables. Means and standard deviations of the observed variables within each sample are shown in Table 3. Box plots of compassionate self-responding values and shameproneness values in each sample are shown in Figures 1 and 2.

Table 3 Means and standard deviations for key study variables within each sample.

\begin{tabular}{lccccccc}
\hline & BPD sample & Eating disorders & $\begin{array}{c}\text { Alcohol } \\
\text { dependents }\end{array}$ & $\begin{array}{c}\text { Healthy } \\
\text { controls }\end{array}$ & $\mathrm{F}$ & $\mathrm{p}$ & $\eta^{2}$ \\
\hline $\begin{array}{l}\text { Compassionate } \\
\text { self-responding }\end{array}$ & $28.00(8.77)$ & $28.36(7.76)$ & $34.22(8.24)$ & $43.11(8.19)$ & 54.885 & $<.001$ & .316 \\
Shame-proneness & $39.32(9.06)$ & $39.85(7.26)$ & $32.95(7.35)$ & $28.26(8.02)$ & 40.317 & $<.001$ & .254 \\
\hline
\end{tabular}


Post-hoc tests (using Bonferroni correction for multiple comparisons) indicated that all clinical samples showed significantly lower compassionate self-responding scores and significantly higher shame-proneness scores compared to healthy controls (all p's $<.001$ ). The magnitudes of difference (Cohen's d values) between all clinical groups and healthy controls were in most cases large (see Table 4). In the case of the alcohol-dependent sample vs. healthy controls, the magnitude of difference in shame-proneness scores was moderate $(d=.61)$.

Table 4 Magnitudes of difference (Cohen's d values) between clinical samples and healthy controls

\begin{tabular}{lrr}
\hline & $\begin{array}{c}\text { Compassionate } \\
\text { self-responding }\end{array}$ & Shame-proneness \\
\hline BPD sample vs. healthy controls & 1.78 & 1.29 \\
Eating disorder sample vs. healthy controls & 1.85 & 1.52 \\
Alcohol-dependent sample vs. healthy controls & 1.08 & .61 \\
\hline
\end{tabular}

\section{Discussion}

This study, in accordance with previous reports, found that patients with borderline personality disorder, eating disorders as well as alcohol-addictions reported significantly lower compassionate self-responding and significantly higher shame-proneness than healthy controls (cf. e.g. Brenner et al., 2018; Braun, Park, \& Gorin, 2016; Brooks et al., 2012; Duarte, Ferreira \& Pinto-Gouveia, 2016; Muris \& Petrocchi, 2017; Peters \& Geiger, 2016; Scheibner et al., 2017). Results showed that the magnitudes of difference in compassionate self-responding and shame-proneness between all clinical samples and healthy controls were moderate to large (see Table 4). Low self-compassion and high shame-proneness were thus demonstrated to be important transdiagnostic factors in these disorders. Moreover, the comparison of results of this study with results reported by Benda, Kadlečík \& Loskotová (2018) shown in Figures 1 and $2^{2}$ further supports the significance of these factors in mental disorders in general. Why did all

\footnotetext{
${ }^{2}$ Figures 1 and 2 were reprinted from Benda (2019), with permission.
} 
clinical samples differ in the levels of compassionate self-responding and shame-proneness from healthy subjects, however?

Fig. 1 Box plots of compassionate self-responding values in each sample compared with results from the study of Benda, Kadlečík \& Loskotová (2018)

Fig. 2 Box plots of shame-proneness values in each sample compared with results from the study of Benda, Kadlečík \& Loskotová (2018)

We hypothesize that implicit belief in the self as a permanent entity (cf. the narrative self) together with the lack of self-compassion leads to the formation of shame whenever one experiences something that is considered to be "wrong" in comparison with one's self-ideal. And since shame is a painful feeling, various defense mechanisms are then automatically activated, resulting in various surface-level psychopathological symptoms (see more details in Benda, 2019). In agreement with Moore et al. (2017), Van Gordon et al. (2018) and other authors, we thus consider maladaptive self-referential processing connected with excessive selfcriticism and lack of self-compassion to be the central cause of all mental disorders examined in this study (cf. e.g. Bernstein, Hadash \& Fresco, 2019; Dambrun, 2017; Dambrun \& Ricard, 2011; Engler \& Fulton, 2012; Lin, Callahan \& Moser, 2018; van Oort et al., 2020). In our opinion, further research of these mechanisms may lead to a new understanding of the etiopathogenesis of these mental disorders as well as to a new understanding of the mechanisms of therapeutic change in these disorders. We assume also that clients suffering from all these disorders may benefit from treatments or particular interventions that facilitate the development of self-compassion or shame management (see e.g. Boersma et al., 2015; Galiana \& Sanso, 2019; Germer \& Neff, 2019; Gilbert, 2010, 2017; Jazaieri et al., 2014; Schoenleber, Gratz, 2018; Van den Brink, Koster \& Norton, 2018). 
It is supposed that self-compassion serves as a protective factor and antidote against shame (e.g. Gilbert, 2017; cf. Johnson \& O'Brien, 2013; Woods \& Proeve, 2014), and our results seem to confirm this assumption, with one exception. In this study, compassionate selfresponding was significantly negatively correlated with shame-proneness in all samples except in the alcohol-dependent sample (see Table 2). However, this is surprisingly consistent with results of some other studies concerning alcohol use, where self-compassion did not serve as a protective factor against alcohol abuse. For example, Brooks et al. (2012) didn't find significant correlations between positive facets of the Self-Compassion Scale and alcohol intake in alcohol addicts. Ellingwood et al. (2019) found that undergraduates who drink scored higher on selfkindness and mindfulness subscales of the Self-Compassion Scale, than those who abstain. Garner et al. (2020) found in a substance use treatment sample that only the mindfulness facet of the Self-Compassion Scale was significantly related to alcohol use over time. Moreover, a recent meta-analysis of 14 samples $(\mathrm{N}=3805)$ found no significant association between shame and substance use $(\mathrm{r}=.00)$. How can this be adequately explained?

The only explanation we have found so far is the possibility that alcohol dependent individuals may interpret the items of the Self-Compassion Scale as well as the items of the shame-proneness subscale of the TOSCA-3S differently than other respondents. To be "kind" to themselves may, for them, mean to allow themselves to drink (see SCS, item 19). To see their failings "as part of the human condition" may mean that others are helpless victims of circumstance just as they believe themselves to be (see SCS, item 15). Furthermore, it is possible that they would not "feel small...like a rat" if they made "fun of a friend who's not there" because they do not admit to themselves at all that such behavior is unfair (see TOSCA3S, item 8a). This explanation would be in line with the fact that we did not find significant correlations between compassionate self-responding or shame-proneness and alcohol dependence symptoms in the alcohol-dependent sample, and also with the fact that research findings 
concerning the relationship of self-esteem and alcohol use have been inconsistent so far (Zeigler-Hill, Dahlen \& Madson, 2017). The abilities to assess one's own attitudes toward the self as well as one's own moral violations seems to be questionable in alcohol dependent individuals. The exact way that alcohol dependent individuals understand the items of SCS and TOSCA-3S should be, therefore, thoroughly examined in the future.

Regarding correlations in the eating disorder sample, we found a correlation $r=.31(\mathrm{p}<$ .05) between shame-proneness and a drive for thinness. However, correlations between shameproneness and bulimia or body dissatisfaction were not significant. This is inconsistent with the results of previous studies which found an association between eating disorder symptoms and shame (e.g. Duarte, Ferreira \& Pinto-Gouveia, 2016; Franzoni et al., 2013). We believe that this is due to the specific nature of some scenarios of the TOSCA-3S (e.g. "You are driving down the road, and you hit a small animal."), which can cause feelings of shame too different from body shame. We therefore recommend verifying the relationship between eating disorder symptoms and shame with the use of other measures in future (e.g. Internalized Shame Scale see Cook, 2001, cf. Benda, Kadlečík \& Loskotová, 2018).

\section{Limitations and Future Directions}

Two main limitations apply to this study. Firstly, as in the study of Benda, Kadlečík \& Loskotová (2018), we used snowball sampling via Facebook with a link to an online questionnaire as recruitment procedure of healthy controls. Results obtained from this sample, thus, may have been affected by volunteer bias. The control sample may be biased, e.g. towards participants with higher motivation levels, more interested in self-knowledge, etc., and may not be representative of the general healthy population. Our results therefore need to be confirmed by future studies using more representative samples of healthy controls. 
Secondly, our findings are based solely on self-report measures and presented correlations thus may be inflated by shared method variance. For further verification of our findings, we therefore recommend to use qualitative research methodologies, evaluating, for example, data from clinical interviews with patients. Apart from that, it is possible that future neuroimaging research may reveal relevant neurobiological processes underlying self-compassion and shameproneness. Especially studies focused on self-referential processing and neural networks responsible for compassion and self-compassion might be beneficial in this regard (see e.g. Frewen et al., 2020; Klimecki, Singer, 2017; Josipovic, 2019; Stevens \& Woodruff, 2018; van Oort et al., 2020).

Despite these limitations, the current study is among the first to simultaneously investigate both self-compassion and shame-proneness in patients with borderline personality disorder, eating disorders, as well as with alcohol-addiction, and we hope it will inspire further research and discussion in this direction. It would be interesting to compare findings of research on self-referential processing, self-compassion, shame and transdiagnostic research, We believe that these so far rather independent research streams have much to offer each other (cf. e.g. Kotov et al., 2017). The same can probably be said for therapies focused on the treatment of shame and on the development of self-compassion (Boersma et al., 2015; Galiana \& Sanso, 2019; Germer \& Neff, 2019; Gilbert, 2010, 2017; Jazaieri et al., 2014; Schoenleber, Gratz, 2018; Van den Brink, Koster \& Norton, 2018). Another interesting comparison could then be made between existing knowledge of self-compassion, shame and some relevant new findings of neuroscience research (see e.g. Gong et al., 2019; Porges, 2011, 2017; Stevens \& Woodruff, 2018). In future questionnaire studies investigating self-referential processing among clinical populations, we recommend to use the Nonattachment to Self Scale (Whitehead et al., 2018). Considering the recent criticism of the Self-Compassion Scale (see e.g. Brenner et al., 2018; Halamová et al., 2020; Muris, Otgaar, Pfattheicher, 2019) we also recommend to replicate our 
findings with the use of the Sussex-Oxford Compassion for the Self Scale in the future (Gu et al., 2020).

\section{References}

Albahari, M. (2016). Analytical Buddhism: The two-tiered illusion of self. New York: Springer.

Amianto, F., Northoff, G., Daga, G. A., Fassino, S., \& Tasca, G. A. (2016). Is anorexia nervosa a disorder of the self? A psychological approach. Frontiers in Psychology, 7, article: 849.

Babor, T. F., Higgins-Biddle, J. C., Saunders, J. B., \& Monteiro, M. G. (2001). AUDIT: The alcohol use disorders identification test: Guidelines for use in primary health care. Geneva: World Health Organization.

Benda, J. (2019). Všímavost a soucit se sebou: Proměna emocí v psychoterapii [Mindfulness and self-compassion: Transforming emotions in psychotherapy]. Praha: Portál.

Benda, J., Kadlečík, P., \& Loskotová, M. (2018). Differences in self-compassion and shame in patients with anxiety disorders, patients with depressive disorders and healthy controls. Československá psychologie, 62(6), 529-541.

Bernstein, A., Hadash, Y., \& Fresco, D. M. (2019). Metacognitive processes model of decentering: emerging methods and insights. Current Opinion in Psychology, 28, 245251.

Boersma, K ., Håkanson, A., Salomonsson, E ., \& Johansson, I. (2015). Compassion focused therapy to counteract shame, self-criticism and isolation. A replicated single case experimental study for individuals with social anxiety. Journal of Contemporary Psychotherapy, 45(2), 89-98.

Braun, T. D., Park, C. L., \& Gorin, A. (2016). Self-compassion, body image, and disordered eating: A review of the literature. Body Image, 17, 117-131. 
Brenner, R. E., Vogel, D. L., Lannin, D. G., Engel, K. E., Seidman, A. J., \& Heath, P. J. (2018). Do self-compassion and self-coldness distinctly relate to distress and well-being? A theoretical model of self-relating. Journal of Counseling Psychology, 65(3), 346-357.

Brooks, M., Kay-Lambkin, F., Bowman, J., \& Childs, S. (2012). Self-compassion amongst clients with problematic alcohol use. Mindfulness, 3(4), 308-317.

Cândea, D., \& Szentagotai, A. (2013). Shame and psychopathology: From research to clinical practice. Journal of Cognitive and Behavioral Psychotherapies, 13(1), 101-113.

Cândea, D. M., \& Szentagotai-Tătar, A. (2018a). Shame-proneness, guilt-proneness and anxiety symptoms: A meta-analysis. Journal of Anxiety Disorders, 58, 78-106.

Cândea, D. M., \& Szentágotai-Tătar, A. (2018b). The impact of self-compassion on shameproneness in social anxiety. Mindfulness, 9(6), 1816-1824.

Cohen, J. (1988): Statistical power analysis for the behavioral sciences. Hillsdale: Erlbaum.

Cook, D. R. (2001). Internalized Shame Scale: Technical manual. North Tonawanda: MultiHealth Systems.

Dahl, C. J., Lutz, A., \& Davidson, R. J. (2015). Reconstructing and deconstructing the self: cognitive mechanisms in meditation practice. Trends in Cognitive Sciences, 19(9), 515523.

Dambrun, M. (2017). Self-centeredness and selflessness: happiness correlates and mediating psychological processes. PeerJ, 5, e3306.

Dambrun, M., \& Ricard, M. (2011). Self-centeredness and selflessness: A theory of self-based psychological functioning and its consequences for happiness. Review of General Psychology, 15(2), 138-157.

Daňsová, P. (2015). Mateřské sebehodnocení v těhotenství: souvislost s vybranými charakteristikami ženy a partnerského vztahu: Diplomová práce. Brno: Fakulta sociálních studií Masarykovy univerzity. 
Daňsová, P., Masopustová, Z., Hanáčková, V., Kicková, K. \& Korábová, I. (2016). Metoda Patient Health Questionnaire-9: česká verze. Československá psychologie, 60(5), 468481.

Duarte, C., Ferreira, C., \& Pinto-Gouveia, J. (2016). At the core of eating disorders: Overvaluation, social rank, self-criticism and shame in anorexia, bulimia and binge eating disorder. Comprehensive Psychiatry, 66, 123-131.

Dvořáková, P. (2013). Tendence k prožívání studu a tendence k prožívání viny jako moderátory vztahu mezi interpersonální závislostí a vyhledáváním sociální opory: Diplomová práce. Brno: Fakulta sociálních studií Masarykovy univerzity.

Ellingwood, L., Espinoza, M. A., Acevedo, M., \& Olson, L. E. (2019). College student drinkers have higher self-compassion scores than nondrinkers. International Journal of Mental Health and Addiction, 17(3), 658-666.

Engler, J., \& Fulton, P. R. (2012). Self and no-self in psychotherapy. In C. K. Germer \& R. D. Siegel (Eds.). Wisdom and compassion in psychotherapy: Deepening mindfulness in clinical practice (pp. 176-188). New York: Guilford.

Ferreira, C., Pinto-Gouveia , J., \& Duarte, C. (2013). Self-compassion in the face of shame and body image dissatisfaction: Implications for eating disorders. Eating Behaviors, 14(2), 207-210.

Franzoni, E., Gualandi, S., Caretti, V., Schimmenti, A., Di Pietro, E., Pellegrini, G., ... \& Pellicciari, A. (2013). The relationship between alexithymia, shame, trauma, and body image disorders: investigation over a large clinical sample. Neuropsychiatric Disease and Treatment, 9, 185-193.

Frewen, P., Schroeter, M. L., Riva, G., Cipresso, P., Fairfield, B., Padulo, C., ... \& Polyakova, M. (2020). Neuroimaging the consciousness of self: Review, and conceptualmethodological framework. Neuroscience \& Biobehavioral Reviews, 112, 164-212. 
Galiana, L., \& Sanso, N. (Eds.) (2019). The Power of Compassion. New York: Nova Science Publishers.

Gallagher, S. (2000). Philosophical conceptions of the self: Implications for cognitive science. Trends in Cognitive Sciences, 4, 12-21.

Garner, A. R., Gilbert, S. E., Shorey, R. C., Gordon, K. C., Moore, T. M., \& Stuart, G. L. (2020). A Longitudinal Investigation on the Relation between Self-Compassion and Alcohol Use in a Treatment Sample: A Brief Report. Substance Abuse: Research and Treatment, 14, 1178221820909356.

Garner, D. M., Olmstead, M. P., \& Polivy, J. (1983). Development and validation of a multidimensional eating disorder inventory for anorexia nervosa and bulimia. International Journal of Eating Disorders, 2(2), 15-34.

Germer, C., \& Neff, K. (2019). Teaching the mindful self-compassion program: A guide for professionals. New York: Guilford.

Gilbert, P. (2010). Compassion focused therapy: Distinctive features. London: Routledge.

Gilbert, P. (2017). Shame and the vulnerable self in medical contexts: the compassionate solution. Medical Humanities, 43(4), 211-217.

Giles, J. (2019). Relevance of the no-self theory in contemporary mindfulness. Current Opinion in Psychology, 28, 298-301.

Gong, Q., Scarpazza, C., Dai, J., He, M., Xu, X., Shi, Y., ... \& Yang, C. (2019). A transdiagnostic neuroanatomical signature of psychiatric illness. Neuropsychopharmacology, 44(5), 869-875.

Gu, J., Baer, R., Cavanagh, K., Kuyken, W., \& Strauss, C. (2020). Development and psychometric properties of the Sussex-Oxford compassion scales (SOCS). Assessment, 27(1), 3-20. 
Halamová, J., Kanovský, M., Petrocchi, N., Moreira, H., López, A., Barnett, M. D., Yang, E., Benda, J., Brähler, E., Zeng, X., \& Zenger, M. (2020) Factor Structure of the SelfCompassion Scale in 11 International Samples, Measurement and Evaluation in Counseling and Development, DOI: 10.1080/07481756.2020.1735203

Jazaieri, H., McGonigal, K., Jinpa, T., Doty, J. R., Gross, J. J., \& Goldin, P. R. (2014). A randomized controlled trial of compassion cultivation training: Effects on mindfulness, affect, and emotion regulation. Motivation and Emotion, 38(1), 23-35.

Johnson, E. A., \& O'Brien, K. A. (2013). Self-compassion soothes the savage ego-threat system: Effects on negative affect, shame, rumination, and depressive symptoms. Journal of Social and Clinical Psychology, 32(9), 939-963.

Josipovic, Z. (2019). Nondual awareness: consciousness-as-such as non-representational reflexivity. Progress in Brain Research, 244, 273-298.

Kelly, A. C., Carter, J. C., \& Borairi, S. (2014). Are improvements in shame and selfcompassion early in eating disorders treatment associated with better patient outcomes? International Journal of Eating Disorders, 47(1), 54-64.

Kim, S., Thibodeau, R., \& Jorgensen, R. S. (2011). Shame, guilt, and depressive symptoms: A meta-analytic review. Psychological Bulletin, 137(1), 68-96.

Klimecki, O. M., \& Singer, T. (2017). The Compassionate Brain. In: Seppälä, E. M., SimonThomas, E., Brown, S. L., Worline, M. C., Cameron, C. D., \& Doty, J. R. (Eds.). The Oxford Handbook of Compassion Science. New York: Oxford University Press.

Kline, R. B. (2015). Principles and practice of structural equation modelling (4th ed.). New York: Guilford Press.

Kotov, R., Krueger, R. F., Watson, D., Achenbach, T. M., Althoff, R. R., Bagby, R. M., Brown, T. A., Carpenter, W. T., Caspi, A., Clark, L. A., Eaton, N. R., Forbes, M. K., Forbush, K. T., Goldberg, D., Hasin, D., Hyman, S. E., Ivanova, M. Y., Lynam, D. R., Markon, K., . 
. Zimmerman, M. (2017). The Hierarchical Taxonomy of Psychopathology (HiTOP): A dimensional alternative to traditional nosologies. Journal of Abnormal Psychology, 126(4), 454-477.

Kroenke, K., Spitzer, R. L., \& Williams, J. B. (2001). The PHQ-9: Validity of a brief depression severity measure. Journal of General Internal Medicine, 16(9), 606-613.

Kroenke, K., Spitzer, R. L., Williams, J. B., \& Löwe, B. (2010). The Patient Health Questionnaire somatic, anxiety, and depressive symptom scales: a systematic review. General Hospital Psychiatry, 32(4), 345-359.

Kyrios, M., Moulding. R., Doron, G., Bhar, S. S., Nedeljkovic, M., \& Mikulincer, M. (Eds.). (2016). The self in understanding and treating psychological disorders. Cambridge: Cambridge University Press.

Lin, Y., Callahan, C. P., \& Moser, J. S. (2018). A mind full of self: Self-referential processing as a mechanism underlying the therapeutic effects of mindfulness training on internalizing disorders. Neuroscience \& Biobehavioral Reviews, 92, 172-186.

López, A., Sanderman, R., \& Schroevers, M. J. (2018). A close examination of the relationship between self-compassion and depressive symptoms. Mindfulness, 9(5), 1470-1478.

Luoma, J. B., Chwyl, C., \& Kaplan, J. (2019). Substance use and shame: A systematic and meta-analytic review. Clinical Psychology Review, 70, 1-12.

Moore, K. E., Christian, M. A., Boren, E. A., \& Tangney, J. P. (2016). A Clinical Psychological Perspective on Hyper-and Hypo-egoicism: Symptoms, Treatment, and Therapist Characteristics. In K. W. Brown, M. R. Leary (Eds.). The Oxford handbook of hypo-egoic phenomena (pp. 95-105). New York: Oxford University Press.

Muris, P., Otgaar, H., \& Pfattheicher, S. (2019). Stripping the forest from the rotten trees: compassionate self-responding is a way of coping, but reduced uncompassionate selfresponding mainly reflects psychopathology. Mindfulness, 10(1), 196-199. 
Muris, P., \& Petrocchi, N. (2017). Protection or vulnerability? A meta-analysis of the relations between the positive and negative components of self-compassion and psychopathology. Clinical Psychology \& Psychotherapy, 24(2), 373-383.

Neff, K. D. (2019). Setting the record straight about the Self-Compassion Scale. Mindfulness, 10(1), 200-202.

Neff, K. D., Long, P., Knox, M., Davidson, O., Kuchar, A., Costigan, A., Williamson, Z., Rohleder, N., Tóth-Király, I., \& Breines, J. (2018). The forest and the trees: examining the association of self-compassion and its positive and negative components with psychological functioning. Self and Identity, 17(6), 627-645.

Papežová, H. (Ed.) (2010). Spektrum poruch př́jmu potravy: Interdisciplinární přístup. Praha: Grada.

Peters, J. R., \& Geiger, P. J. (2016). Borderline personality disorder and self-conscious affect: Too much shame but not enough guilt? Personality Disorders: Theory, Research, and Treatment, 7(3), 303-308.

Porges, S. W. (2011). The polyvagal theory: Neurophysiological foundations of emotions, attachment, communication, and self-regulation. New York: W. W. Norton \& Company. Porges, S. W. (2017). Clinical insights from the polyvagal theory: The transformative power of feeling safe. New York: W. W. Norton \& Company.

Ritter, K., Vater, A., Rüsch, N., Schröder-Abé, M., Schütz, A., Fydrich, T., ... \& Roepke, S. (2014). Shame in patients with narcissistic personality disorder. Psychiatry Research, 215(2), 429-437.

Scheel, C. N., Bender, C., Tuschen-Caffier, B., Brodführer, A., Matthies, S., Hermann, C., ... \& Jacob, G. A. (2014). Do patients with different mental disorders show specific aspects of shame? Psychiatry Research, 220(1-2), 490-495. 
Scheibner, H. J., Daniels, A., Guendelman, S., Utz, F., \& Bermpohl, F. (2017). SelfCompassion Mediates the Relationship Between Mindfulness and Borderline Personality Disorder Symptoms. Journal of Personality Disorders, 31, 1-19.

Schoenleber, M., \& Gratz, K. L. (2018). Self-acceptance group therapy: A transdiagnostic, cognitive-behavioral treatment for shame. Cognitive and Behavioral Practice, 25(1), 75 86.

Shapiro, S., Siegel, R., \& Neff, K. D. (2018). Paradoxes of Mindfulness. Mindfulness, 9(6), $1693-1701$.

Shonin, E., Van Gordon, W., \& Griffiths, M. D. (2016). Ontological addiction: classification, etiology, and treatment. Mindfulness, 7(3), 660-671.

Sovinová, H., \& Csémy, L. (2010). The Czech audit: internal consistency, latent structure and identification of risky alcohol consumption. Central European Journal of Public Health, $18(3), 127-131$.

Spitzer, R. L., Kroenke, K., Williams, J. B., \& Löwe, B. (2006). A brief measure for assessing generalized anxiety disorder: the GAD-7. Archives of Internal Medicine, 166(10), $1092-$ 1097.

Stevens, L., \& Woodruff, C. Ch. (Eds.) (2018). The neuroscience of empathy, compassion, and self-compassion. London: Academic Press.

Tangney, J. P., \& Dearing, R. (2002). Shame and Guilt. New York: Guilford.

Thompson, E. (2014). Waking, dreaming, being: Self and consciousness in neuroscience, meditation, and philosophy. New York: Columbia University Press.

Van den Brink, E., Koster, F., \& Norton, V. (2018). A Practical Guide to Mindfulness-Based Compassionate Living: Living with heart. New York: Routledge. 
Van Gordon, W., Shonin, E., Diouri, S., Garcia-Campayo, J., Kotera, Y., \& Griffiths, M. D. (2018). Ontological addiction theory: Attachment to me, mine, and I. Journal of Behavioral Addictions, 7(4), 892-896.

van Oort, J., Kohn, N., Vrijsen, J. N., Collard, R., Duyser, F. A., Brolsma, S. C. A., ... \& van Eijndhoven, P. F. (2020). Absence of default mode downregulation in response to a mild psychological stressor marks stress-vulnerability across diverse psychiatric disorders. NeuroImage: Clinical, 25, article: 102176.

Whitehead, R., Bates, G., Elphinstone, B., Yang, Y., \& Murray, G. (2018). Letting go of self: The creation of the Nonattachment to Self Scale. Frontiers in Psychology, 9, article: 2544. Winter, U., LeVan, P., Borghardt, T. L., Akin, B., Wittmann, M., Leyens, Y., \& Schmidt, S. (2020). Content-free Awareness: EEG-fcMRI Correlates of Consciousness as such in an Expert Meditator. Frontiers in Psychology, 10, article: 3064.

Woods, H., \& Proeve, M. (2014). Relationships of mindfulness, self-compassion, and meditation experience with shame-proneness. Journal of Cognitive Psychotherapy, 28(1), 20-33.

World Health Organization (1992). International statistical classification of diseases and related health problems: 10th revision (ICD-10) (Vol. 1). Geneva: World Health Organization.

Zeigler-Hill, V., Dahlen, E. R., \& Madson, M. B. (2017). Self-esteem and alcohol use: Implications for aggressive behavior. International Journal of Mental Health and Addiction, 15(5), 1103-1117. 